\title{
Food Powder Manufacture from Grape Pomace and its Application as an Improver in the Macaroni Production
}

\author{
N.V. Yavruyan, N.A. Avetisyan \\ Armenian National Agrarian University \\ naira.yavruyan@mail.ru, naraavetisyan97@gmail.com
}

\section{A R T I CLE I N F O}

\section{Keywords:}

pasta products,

grape pomace,

improver,

nutrition powder

from grape pomace,

grape pomace powder

application

\begin{abstract}
A B S T RA C T
A number of dietary and functional food products are manufactured by macaroni producing enterprises, which are presented in trade network, but their percentage ratio is still small.

Nutritional and biological value of macaroni products can be enhanced due to the introduction of non-traditional raw materials and specific food additives in the recipe.

Based on this, a concept for developing high quality and nutrient value macaroni production technology is recommended, which is related to the selection of nontraditional raw material. The novelty of the research is that the grape pomace powder is going to be used as an additive with high nutritional value.
\end{abstract}

\section{Introduction}

Food quality and balanced diet of a person have a crucial role in the health care and life quality of humanity. Pasta products are in great demand among all groups of population, and hence, they can be considered as an object for being enriched with functional ingredients.

A number of food products supplemented with dietary or functional components are manufactured by macaroni producing enterprises, which are introduced in the trade network but their amount is rather small in percentage ratio. Taking into account the high demand for macaroni products, the opportunity of including non-traditional raw materials for the change of food chemical composition and increase of its nutritional value can be considered as a perspective direction (Avetisyan, 2015). The food nutritional and biological value can be enhanced by including non-traditional raw materials and specific food additives in the recipes. The aim of the current work is to improve the technology of producing food powders from the grape husks and seeds and to apply them in the technology for manufacturing high nutrient value macaroni products.

\section{Materials and methods}

Pasta products possess several advantages over the other flour products, i.e. high digestibility of the essential nutrients, long shelf life, low cost and availability for any population strata. 
The investigations have shown that poor chemical composition of the pasta produced from the bread flour characterizing their nutritional value, points to the need for supplementing the mentioned products with such foodstuffs, as protein, essential amino-acids, food fibers, vitamins and mineral substances.

Therefore, a concept for developing a technology for producing high quality macaroni product with high nutritional value has been recommended based on the selection of non-traditional raw material type. It aims to justify the use of grape pomace food powder as a plantbased raw material in the pasta production with high biological value, to determine their effect on the wheat flour and to evaluate the application efficiency of grape pomace powder in enhancing the qualitative properties of the new type of macaroni products (Sedrakyan, 2017).

Studying different literature sources, we have found out that the grape pomace is one of the prior sources for food powder manufacture, which contains up to $20 \%$ cellulose and 5-8 \% pectic substances and which is not practically processed in the primary wineries (Perkovets, 2008).

Upon the study of chemical composition of grape pomace, it has been disclosed that its dry mass contains monosaccharides (4.03\%), lignine (soluble, $28.4 \%$ ), water-soluble polysaccharides $(6.56 \%)$, hemicelluloses (A, B) and nitrogenous bases $(0.22 \%)$.

Carbohydrates manifested through mono- and disaccharides, pectic substances and cellulose are the main components of the grape pomace. Cellulose together with insulin decreases the blood glucose level.

Food fibers reduce the food digestibility and increase the energy consumption during metabolism enabling to decrease the weight of the people suffering from obesity.

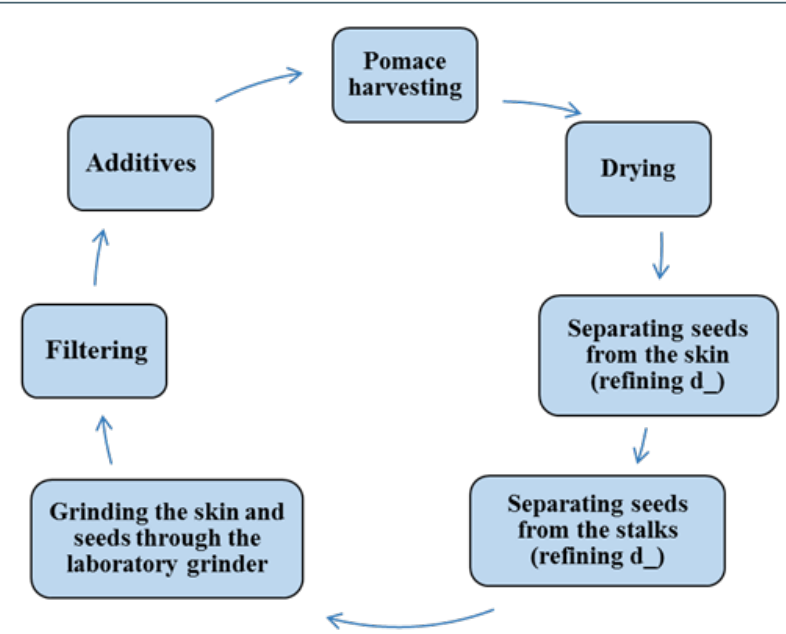

Figure 1. The scheme of producing powder from the grape pomace (composed by the authors).
The technological scheme of producing grape pomace powder was developed in laboratory conditions, which is introduced in Figure 1.

After producing food powder from the pomace of thered grape varieties (Kakhet, Kangun, Rkatsiteli), its chemical composition was determined and evaluated, which is presented in Table 1.

Table 1. Chemical composition of the food powders produced from the red grape pomace*

\begin{tabular}{|c|c|c|c|}
\hline \multirow{2}{*}{ Indicator } & \multicolumn{3}{|c|}{ Pomace variety } \\
\hline & Kakhet & Kangun & Rkatsiteli \\
\hline $\begin{array}{l}\text { Mass composition of } \\
\text { carbohydrates, } \% \text {, including }\end{array}$ & 64.8 & 71.4 & 60.9 \\
\hline Pectic substances, $\%$ & 6.3 & 8.3 & 7.8 \\
\hline Cellulose, $\%$ & 16.8 & 20.8 & 19.4 \\
\hline $\begin{array}{l}\text { Mass composition of acids, } \\
\%\end{array}$ & 8.2 & 6.8 & 9.3 \\
\hline Tannins and dyestuffs, $\%$ & 2.1 & 0.2 & 0.3 \\
\hline \multicolumn{4}{|c|}{ The content of mineral substances } \\
\hline Iron, mg \% & 18.31 & 11.25 & 12.88 \\
\hline Manganese, mg \% & 1.36 & 1.08 & 1.25 \\
\hline Zink, mg \% & 3.37 & 6.2 & 5.8 \\
\hline Copper, mg \% & 2.1 & 1.5 & 1.2 \\
\hline Iodine, $\operatorname{mcg} \%$ & 36 & 30 & 28 \\
\hline Sodium, mg \% & 7.85 & 10.25 & 9.81 \\
\hline Potassium, mg \% & 812.5 & 760.4 & 770.1 \\
\hline Calcium, mg \% & 83.3 & 77.7 & 63.3 \\
\hline Magnesium, mg \% & 91.3 & 72.8 & 68.9 \\
\hline \multicolumn{4}{|l|}{ Content of vitamins, $\mathrm{mg} \%$} \\
\hline $\mathrm{C}$ & 17.6 & 14.1 & 12.3 \\
\hline$\beta$-carotene & 18.9 & 16.1 & 14.8 \\
\hline B6 & 0.09 & 0.07 & 0.06 \\
\hline
\end{tabular}

As it is shown in Table 1, the main constituents of the produced supplement are carbohydrates coming forth as pectic substances and cellulose. The grape pomace powders contain a large number of vitamins and mineral substances which penetrate in all live cells and structural tissue particles, as well as in the biologically vital ferments and take part in metabolism. Special attention should be paid to the high content of dietary fibers in the grape pomace powder, which have fortifying effect over the flour gluten and positive impact on the human body. Nowadays food fibers are the most highly-demanded and widespread 
food components due to their multifunctionality. It is well known that fibers are subdivided into water-soluble and insoluble ones. The main representative of the so-called "rigid fibers" is the cellulose, which constitutes the grape pomace.

To accomplish the task the experimental pasta sample was prepared through the following scheme including the mentioned phases (Figure 2).

Based on the conducted investigations it has been asserted that the rational cellulose portion, which mostly has positive impact on the properties of wheat flour gluten and on the quality of finished pasta products, makes $25 \%$.

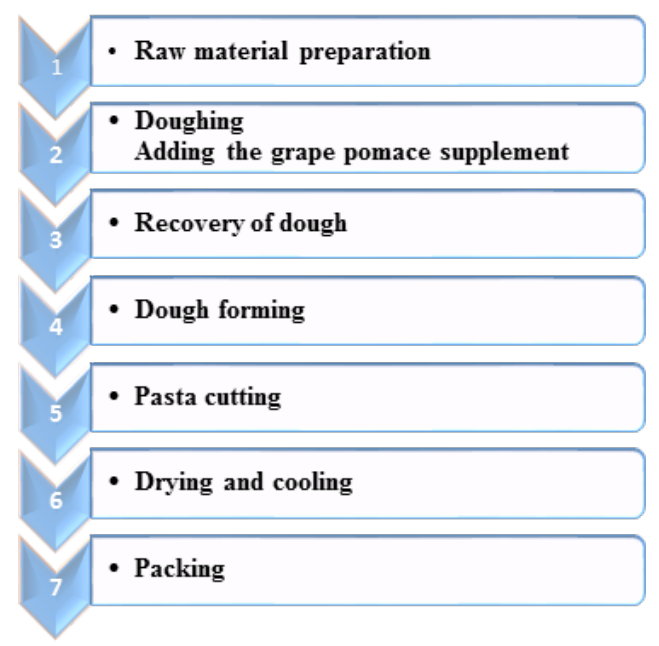

Figure 2. The scheme of experimental pasta production (composed by the authors).

\section{Results and discussions}

The dough without any supplement served as a control variant, while in the dough of experimental samples grape pomace with the ratio of up to $15-25 \%$ was used. The study results related to the effect of different ratios of grape pomace on the "strength" of the wheat flour are introduced in Table 2.

The result analysis has indicated that as compared to the control variant the gluten content in the flour of experimental samples is somehow reduced in case of cellulose introduction. Besides, the elastic property of the gluten increases by $12.9 \%-40.9 \%$ in respect to cellulose ratio against the control variant. The cohesive force of the gluten grows up by $1.1 \%-56.0 \%$. The proven effect of cellulose is due to its ability to form protein polysaccharide complexes with wheat flour proteins, which leads to an increase in its strength.
Despite the considerable elasticity increase in the gluten, its hydrating ability grows up by $2.4 \%-18.0 \%$ against the cellulose. This is due to the physicochemical properties of food fibers, particularly to its water retention property.

Table 2. The effect of different ratios of grape pomace on the quality and quantity of the flour gluten*

\begin{tabular}{|c|c|c|c|c|}
\hline \multirow[t]{2}{*}{$\begin{array}{l}\text { Indicator } \\
\text { name }\end{array}$} & \multirow[t]{2}{*}{ Control } & \multicolumn{3}{|c|}{$\begin{array}{c}\text { Samples with the } \\
\text { supplementation of grape } \\
\text { pomace powder, amount \% } \\
\text { from flour mass }\end{array}$} \\
\hline & & 15 & 20 & 25 \\
\hline $\begin{array}{l}\text { Gluten } \\
\text { content, \% }\end{array}$ & $29.3+0.1$ & $28.5+0.1$ & $28.1+0.1$ & $27.5+0.1$ \\
\hline Elasticity & \multicolumn{4}{|c|}{ good } \\
\hline $\mathrm{GDM}^{*}$ unit & 64.5 & 56.0 & 53.5 & 54.0 \\
\hline $\begin{array}{l}\text { Hydration } \\
\text { capacity, \% }\end{array}$ & $156.25_{-}^{+0.75}$ & $159.8+0.75$ & $165.1+0.75$ & $172.5 \pm 0.75$ \\
\hline $\begin{array}{l}\text { Cohesive } \\
\text { force, } \mathrm{H}\end{array}$ & 4.8 & 4.85 & 5.35 & 5.9 \\
\hline
\end{tabular}

In mid-strength pasta producing factories the drying process is mostly implemented in the drying cabinet stations by having pasta spread in the special frames and continuously replacing the mass from one rack to another through the continuously working conveyer stations with the conveyer belt. In the drying cabinet the gradually decreasing drying temperature (heat agent) regime (from $65{ }^{0} \mathrm{C}$ to $35-38{ }^{\circ} \mathrm{C}$ ) was applied within 5.3-5.5 hours with further stabilization within 90-120 minutes time duration. The qualitative indices of the pasta products determined in the result of the experiments are presented in Table 3.

The quality of the finished pasta products have been characterized per the strength of dry product types, their cooking properties, and per the humidity of the product after cooking. The organoleptic evaluation of the cooked macaroni products has been conducted according to the basic quality assessment scale. The analyses of the obtained results also show that when introducing fortifying additives improvement of cooking properties occur in the experimental samples as compared to those of the control variant. The cooking period which lasts up to the fabrication of the finished product insignificantly differs from that of the control sample. The experiments have confirmed that in the sample with the content of $25 \%$ grape pomace the coefficient of pasta mass grows up. It has been also proved that in the same sample the dry matters penetrated in the boiling water are reduced. This 
process is due to over-strengthening of gluten. The content of dry matters in the boiling water is reduced by $0.93 \%$ on the average against that of registered in the control variant. The mentioned indicator is reduced by maximum amounts (by $1.12 \%$ against the control variant) when $25 \%$ cellulose is introduced. The quality indices of the pasta products supplemented with grape pomace are introduced in Table 4.

Table 3. Qualitative indices of the pasta products*

\begin{tabular}{|l|l|c|}
\hline $\mathbf{N}$ & \multicolumn{1}{|c|}{ Indicators } & \multicolumn{1}{|c|}{$\begin{array}{c}\text { Product } \\
\text { Noodles }\end{array}$} \\
\hline 1. & $\begin{array}{l}\text { Product diameter (wall } \\
\text { thickness), mm }\end{array}$ \\
\hline 2. & Breakage, \% & 3 \\
\hline 3. & Color & n/a \\
\hline 4. & Surface & Brown with a dash of violet \\
\hline 5. & Humidity, \% & Smooth \\
\hline 6. & Shape retention & $12.8+0.2$ \\
\hline 7. & $\begin{array}{l}\text { Cooking time, until } \\
\text { ready, minute }\end{array}$ \\
\hline 8. & $\begin{array}{l}\text { Dry matter content in } \\
\text { the boiling water, } \%\end{array}$ \\
\hline 9. & Color index & $8.8-7.2$ \\
\hline
\end{tabular}

Table 4. Quality indices of the pasta products supplemented with grape pomace powder*

\begin{tabular}{|c|c|c|}
\hline \multirow[t]{2}{*}{ Indicator } & \multicolumn{2}{|c|}{$\begin{array}{l}\text { The quality indices of the } \\
\text { pasta products manufactured } \\
\text { through the mixture of flour } \\
\text { and grape pomace powder, } \\
\text { with the ratio }\end{array}$} \\
\hline & 100:0 (control) & $100: 25$ \\
\hline Strength of dry product, $\mathrm{H}$ & $2.8+0.2$ & $3.8+0.2$ \\
\hline Cooking time, minute & 7.0 & 8 \\
\hline $\begin{array}{l}\text { Loss of dry matters in the } \\
\text { boiling water, } \%\end{array}$ & $8.3 \pm 0.2$ & $8.7 \pm 0.2$ \\
\hline Coefficient of mass increase & $2.89 \pm 0.03$ & $2.96 \pm 0.03$ \\
\hline Humidity of dry products, $\%$ & $13.0+0.1$ & $13.0 \pm 0.1$ \\
\hline $\begin{array}{l}\text { Product humidity after } \\
\text { cooking, \% }\end{array}$ & $66.4+0.2$ & $67.0 \pm 0.2$ \\
\hline Acidity, degree & $2.2+0.2$ & $2.2+0.2$ \\
\hline $\begin{array}{l}\text { Organoleptic evaluation, } \\
\text { point }\end{array}$ & 86.0 & 88.0 \\
\hline
\end{tabular}

So, by adding $25 \%$ grape pomace powder in the pasta the strength of dry product has increased by $35.7 \%$ as compared to the control variant, the cooking time - by one minute, while the loss of dry matters has grown up by $4.8 \%$, pasta mass growing coefficiet has increased by $2.4 \%$ and the humidity of the cooked pasta - by $0.9 \%$. Besides, by adding the grape pomace powder, the organoleptic evaluation indices of the pasta products have exceeded those of the control variant due to the shape retention of the products during the cooking process. The quality of pasta acquired through adding grape pomace powder complies with the standards of GOST 51865-2002 (GOST R 51865-2002 Macaroni products).

\section{Conclusion}

Upon the research results the following conclusions can be inferred:

- The chemical composition of the food powders produced from the dried pomace of various red grape varieties has been studied and their safety indices have been determined. Per a number of safety and microbiological indices it has been clearly stated that the food powder manufactured from grape pomace can serve as a useful additive increasing the nutritional value of the macaroni products.

- It has been proved that supplementation of $25 \%$ grape pomace powder will enable to increase the content of dietary fiber in the finished product in about 45 times.

- The quality and physicochemical indices of the new macaroni products comply with the requirements of the current normative documents.

\section{References}

1. Avetisyan, M.H. (2015). Improvement of Short Pasta (Pasta Corta) Production Technology, Development of New Recipes and Drying Regimes. Thesis Work. Yerevan.

2. GOST R 51865-2002 Macaroni Products. Common Technical Conditions / GOST R from January 30, 2002, - № 51865-2002.

3. Perkovets, M.V. (2008). New Ingredients for Functional Bakery and Pasta Products - Natural Prebiotics [Text] / M. V. Perkovets // Food Ingredients, Raw Materials and Additives, - № 1, - pp. 38-39 (in Russian).

4. Sedrakyan, A. (2017). Developing and Improving Grape Pomace Dryng Method for the Production of Food Additive // Materials of International Scientific Internet Conference, Current Scientific Research Works in the Modern World // Ukraine, Pereyaslav-Khmelnytskiy: iScience, May 26-27, - pp. 97-103. 